\title{
Pemanfaatan Kulit Biji Hanjeli (Coix lacryma-jobiL.) sebagai Pupuk Silika Organik terhadap Pertumbuhan, Serapan P dan Si, serta Hasil Hanjeli pada Inceptisol Jatinangor
}

\author{
Zaenal Mutaqin ${ }^{1}$, Anni Yuniarti², Tati Nurmala ${ }^{3}$ dan Eso Solihin ${ }^{2}$ \\ ${ }^{1}$ Alumni Program Pascasarjana Ilmu Tanah, Fakultas Pertanian, Universitas Padjadjaran \\ ${ }^{2}$ Departemen Ilmu Tanah dan Sumber Daya Lahan, Fakultas Pertanian, \\ Universitas Padjadjaran \\ ${ }^{3}$ Departemen Budidaya Tanaman, Fakultas Pertanian, Universitas Padjadjaran \\ *Alamat korespondensi: zaenal.00025@gmail.com
}

\author{
ABSTRACT \\ Utilization of hanjeli seed skin as organic silica fertilizer in influencing the growth, $\mathrm{P}$ and $\mathrm{Si}$ \\ absorption, and yield of hanjeli (Coix lacryma-jobi L.)
}

This experiment was conducted to determine the effect of hanjeli seed shell as organic silica fertilizer on plant uptake and hanjeli pulut (Coix lacryma-jobi L.) yield on Inceptisol. The experiment was conducted in Experimental Station of Agriculture Faculty of Universitas Padjadjaran, Jatinangor, Sumedang Regency, West Java Province. The research was carried out in the altitude of 822 meters above sea level (asl) from May 2017 to October 2017. The method used was a Randomized Block Design (RBD) consisting of ten treatments with three replications, i.e. control, NPK standard, NPK $+1 / 4$ silica emulsion, NPK $+1 / 2$ silica emulsion, NPK $+3 / 4$ silica emulsion, NPK +1 emulsion of ash silica, NPK $+1 / 4$ nano colloidal silica, NPK $+1 / 2$ nano colloidal silica, NPK + 3/4 nano colloidal silica, and NPK + 1 nano colloidal silica. The results showed that the application of silica fertilizer influenced the absorption and the yield of hanjeli plant. The treatment of NPK +1 colloidal nano silica gave the highest hanjeli yield of $210.63 \mathrm{~g} / \mathrm{plant}$.

Keywords: Hanjeli seed skin, Organic silica fertilizer, Plant absorption, Yield

\begin{abstract}
ABSTRAK
Percobaan ini dilakukan untuk mengetahui pengaruh pemberian kulit biji hanjeli sebagai pupuk silika organik terhadap pertumbuhan, serapan tanaman, dan hasil hanjeli pulut (Coix lacryma-jobi L.) pada Inceptisol. Percobaan dilaksanakan di Kebun Percobaan Fakultas Pertanian, Universitas Padjadjaran, Jatinangor, Kabupaten Sumedang, Provinsi Jawa Barat. Lokasi penelitian berada pada ketinggian 822 meter di atas permukaan laut (dpl) pada bulan Mei 2017 sampai dengan Oktober 2017. Metode yang digunakan adalah Rancangan Acak Kelompok (RAK) yang terdiri dari sepuluh perlakuan dengan tiga kali ulangan yaitu kontrol, NPK standar, NPK + 1/4 emulsi abu silika, NPK + $1 / 2$ emulsi abu silika, NPK + 3/4 emulsi abu silika, NPK +1 emulsi abu silika, NPK + 1/4 nano koloid silika, NPK + 1/2 nano koloid silika, NPK + 3/4 nano koloid silika, serta NPK + 1 nano koloid silika. Hasil penelitian menunjukkan bahwa terdapat pengaruh pemberian pupuk silika organik terhadap serapan P, Si tanaman dan hasil hanjeli. Perlakuan NPK +1 nano koloid silika memberikan Serapan $\mathrm{P}, \mathrm{Si}$ tanaman serta hasil hanjeli tertinggi dengan nilai masing-masing sebesar 0,61 $\mathrm{g} /$ tanaman, 7,56 g/tanaman, dan 210,63 g/tanaman.
\end{abstract}

Kata Kunci: Kulit biji hanjeli, Pupuk Silika Organik, Serapan dan Hasil Hanjeli 


\section{PENDAHULUAN}

Pangan merupakan kebutuhan dasar hidup manusia. Seiring dengan peningkatan jumlah penduduk, maka kebutuhan pangan juga akan meningkat. Laporan dari Badan Pusat Statistik menunjukkan bahwa jumlah penduduk Indonesia dari tahun ke tahun terus meningkat. Pada tahun 2009, jumlah penduduk Indonesia mencapai 123 juta jiwa dan tahun 2014 jumlah penduduk kembali meningkat sebesar 132 juta jiwa (BPS, 2014). Selama ini kebijakan pangan nasional hanya pada beras saja, sehingga kebutuhan beras terus meningkat. Untuk memenuhi kebutuhan beras tersebut pemerintah bahkan harus melakukan impor beras dari negara lain. Indonesia sudah sejak lama menjadi negara pengimpor beras. Menurut laporan dari Badan Pusat Statistik, pada tahun 2015 Indonesia telah mengimpor beras sebanyak 1,41 juta ton (BPS, 2016).

Perubahan arah pola pangan masyarakat yang selama ini mengkonsumsi beras sebagai sumber karbohidrat utama, harus berpindah ke sumber karbohidrat alternatif, sehingga pemerintah perlu mengembangkan dan memanfaatkan tanaman pangan sumber karbohidrat alternatif yang potensial untuk dikembangkan. Indonesia sendiri memiliki potensi yang sangat besar untuk pengembangan beragam tanaman yang memiliki sumber karbohidrat alternatif (non beras) untuk menunjang diversifikasi pangan, diantaranya hanjeli, jawawut, soba, millet, ganyong, dan lain-lain (Nurmala, 2011).

Hanjeli (Coix lacryma-jobi L.) merupakan tanaman penghasil yang potensial dan memiliki prospek yang baik untuk dikembangkan sebagai sumber bahan pangan alternatif di Indonesia. Tanaman ini memiliki manfaat yang cukup banyak. Hanjeli merupakan tanaman serealia dari famili Graminae yang dapat dimanfaatkan sebagai bahan pangan dan pakan (Nurmala, 1998). Hanjeli termasuk ke dalam suku padi-padian atau famili Graminae yang merupakan jenis tanaman akumulator silika (Si). Tanaman akumulator $\mathrm{Si}$ membutuhkan unsur Si dalam jumlah banyak untuk pertumbuhannya. Si berperan dalam meningkatkan fotosintesis dan resistensi terhadap cekaman biotik dan abiotik. Menurut Nurmala (1998), hanjeli dapat tumbuh baik pada dataran rendah maupun dataran tinggi. Daerah asal hanjeli yaitu dari Asia Timur termasuk Indomalaya (Indonesia).

Indonesia merupakan daerah tropis yang didominasi oleh lahan suboptimal, salah satunya adalah Inceptisol. Inceptisol merupakan salah satu ordo tanah yang tersebar paling luas di Indonesia, sekitar 70,52 juta ha atau 37,5\% dari wilayah daratan Indonesia (Balai Besar Litbang Sumberdaya Lahan Pertanian, 2006). Penyebaran Inceptisol di Jawa Barat salah satunya terdapat di daerah Jatinangor.

Berkaitan dengan tanaman hanjeli, Inceptisol juga mempunyai ketersediaan Si yang sangat rendah. Oleh karena itu diperlukan upaya agar unsur hara yang dibutuhkan tanaman terpenuhi, salah satunya dengan memberikan pupuk silika organik cair, dengan harapan dapat menyediakan unsur $\mathrm{Si}$ serta meningkatkan hasil tanaman hanjeli. Hal ini karena aplikasinya yang disemprotkan melalui daun penyerapan haranya oleh tanaman lebih cepat dibanding pupuk yang diberikan lewat akar (Lingga \& Marsono, 2007).

Salah satu sumber silika yang digunakan pada penelitian ini berasal dari hasil ekstaksi kulit biji hanjeli yang sudah dilakukan melewati proses penyosohan. Namun mengingat tanaman hanjeli belum banyak dikenal oleh masyarakat Indonesia, sehingga proses pengembangan untuk tanaman ini masih sangat minim. Berdasarkan uraian di atas, diharapkan dengan diberikannya silika dari hasil ekstraksi kulit biji hanjeli sebagai pupuk silika bisa dijadikan alternatif yang perlu dipertimbangkan dalam usaha meningkatkan hasil terutama tanaman hanjeli.

\section{BAHAN DAN METODE}

\begin{tabular}{llcc}
\multicolumn{2}{c}{ Penelitian ini dilakukan } & di Kebun \\
Percobaan Fakultas & Pertanian, & Universitas \\
Padjadjaran, Jatinangor, Kabupaten & Sumedang,
\end{tabular} Provinsi Jawa Barat. Lokasi penelitian berada pada ketinggian 822 meter di atas permukaan laut (dpl). Percobaan ini dilakukan dari bulan Mei sampai dengan Oktober 2017. Benih hanjeli yang digunakan adalah hanjeli Pulut genotip 37 yang merupakan koleksi Laboratorium Produksi dan Pemuliaan Tanaman, Fakultas Pertanian, Universitas Padjadjaran. Pupuk Urea $(46 \% \mathrm{~N})$ yang digunakan adalah $300 \mathrm{~kg} / \mathrm{ha}$, pupuk SP-36 (36\% $\left.\mathrm{P}_{2} \mathrm{O}_{5}\right)$ sebanyak $100 \mathrm{~kg} / \mathrm{ha}$ dan pupuk $\mathrm{KCl}\left(50 \% \mathrm{~K}_{2} \mathrm{O}\right) 50 \mathrm{~kg} / \mathrm{ha}$. Pupuk emulsi abu silika disiapkan dengan cara melarutkan $6 \mathrm{~g}$ abu kulit biji hanjeli di dalam 1 liter air (300 ppm), sementara itu pupuk koloid nano silika sebanyak $15 \mathrm{ml}$ dilarutkan dalam 1 liter air (150 ppm).

Metode yang digunakan adalah Rancangan Acak Kelompok (RAK) yang terdiri dari sepuluh perlakuan dengan tiga kali ulangan yaitu kontrol, NPK standar, NPK + 1/4 emulsi abu silika, NPK + 1/2 
emulsi abu silika, NPK + 3/4 emulsi abu silika, NPK + 1 emulsi abu silika, NPK $+1 / 4$ nano koloid silika, NPK $+1 / 2$ nano koloid silika, NPK $+3 / 4$ nano koloid silika, serta NPK + 1 nano koloid silika. Pada penelitian ini, terdapat dua unit percobaan yaitu satu unit untuk pengamatan pada fase vegetatif maksimum dan tiga unit lagi digunakan untuk pengamatan sampai fase generatif akhir. Dengan demikian, total pot percobaan yang digunakan adalah 120 pot percobaan.

\section{HASIL DAN PEMBAHASAN}

\section{Tinggi Tanaman Hanjeli}

Tinggi tanaman hanjeli diukur pada setiap fase pertumbuhan yaitu 5, 7, 9 dan 11 minggu setelah tanam (MST). Pengukuran tinggi tanaman hanjeli merupakan salah satu parameter yang penting karena merupakan ciri pertumbuhan tanaman yang berkaitan dengan faktor dan komponen tumbuh lainnya, seperti lingkungan yang menekan atau mendorong pertumbuhan, perakaran serta anakan yang akan berkembang. Tinggi tanaman sesuai dengan sifat genetiknya sangat relevan dengan produktivitas hasil tanaman itu serta lingkungan tumbuh yang memengaruhinya. Tanaman yang tinggi akan berpengaruh pada sifat saling menaungi di antara susunan daun yang tumbuh dan belum tentu akan menghasilkan biji hanjeli secara maksimum. Rosmarkam dan Yuwono (2002), yang mengatakan bahwa tinggi tanaman dipengaruhi oleh ketersediaan unsur hara dan penyerapan unsur hara oleh akar tanaman, akar berperan penting karena akar berfungsi sebagai penyerap unsur hara dan translokasi unsur dari akar ke batang, daun, ataupun buah. Perkembangan tinggi tanaman berdasarkan data pengamatan dapat dilihat pada Tabel 1.

Tabel 1. Pengaruh pemanfaatan kulit biji hanjeli sebagai pupuk silika organik terhadap tinggi tanaman hanjeli.

\begin{tabular}{lcccc}
\hline \multicolumn{1}{c}{ Perlakuan } & $5 \mathrm{MST}$ & $7 \mathrm{MST}$ & $9 \mathrm{MST}$ & $11 \mathrm{MST}$ \\
\hline Kontrol & & & & \\
NPK Standar & $29,58 \mathrm{~b}$ & $56,67 \mathrm{~b}$ & $83,17 \mathrm{~b}$ & $113,75 \mathrm{~b}$ \\
NPK + 1/4 emulsi abu silika & $38,83 \mathrm{~cd}$ & $62,67 \mathrm{~cd}$ & $92,17 \mathrm{~cd}$ & $122,75 \mathrm{~cd}$ \\
NPK + 1/2 emulsi abu silika & $42,58 \mathrm{de}$ & $65,08 \mathrm{de}$ & $95,25 \mathrm{~d}$ & $126,08 \mathrm{cde}$ \\
NPK + 3/4 emulsi abu silika & $48,58 \mathrm{fg}$ & $70,83 \mathrm{fg}$ & $102,17 \mathrm{ef}$ & $133,50 \mathrm{ef}$ \\
NPK + 1 emulsi abu silika & $52,50 \mathrm{gh}$ & $73,58 \mathrm{~g}$ & $105,92 \mathrm{f}$ & $138,50 \mathrm{fg}$ \\
NPK + 1/4 koloid nano silika & $34,83 \mathrm{c}$ & $59,42 \mathrm{bc}$ & $87,08 \mathrm{bc}$ & $117,83 \mathrm{bc}$ \\
NPK + 1/2 koloid nano silika & $45,58 \mathrm{ef}$ & $67,58 \mathrm{ef}$ & $97,50 \mathrm{de}$ & $129,42 \mathrm{de}$ \\
NPK + 3/4 koloid nano silika & $55,92 \mathrm{~h}$ & $79,08 \mathrm{~h}$ & $112,58 \mathrm{~g}$ & $146,54 \mathrm{~g}$ \\
NPK + 1 koloid nano silika & $61,33 \mathrm{i}$ & $84,25 \mathrm{~h}$ & $123,92 \mathrm{~h}$ & $157,33 \mathrm{~h}$ \\
\hline
\end{tabular}

Keterangan: Angka rerata yang diikuti huruf yang sama tidak berbeda nyata berdasarkan Uji Jarak Berganda Duncan pada taraf 5\%.

Berdasarkan Tabel 1, terlihat bahwa respon tanaman hanjeli terhadap perlakuan terlihat mulai pada umur 5 MST, keragaman tinggi terlihat sampai fase vegetatif akhir (11 MST). Pada fase vegetatif akhir terlihat tanaman tertinggi ditunjukkan oleh perlakuan NPK + 1 koloid nano silika dan umumnya tanaman dengan satu dosis silika memiliki tinggi yang lebih tinggi daripada perlakuan yang takaran silika di bawah satu dosis $(1 / 4,1 / 2$, dan $3 / 4$ silika). Sejalan dengan pernyataan Martanto (2001) Si berperan dalam memperbaiki ketegakan tanaman, sehingga terjadi peningkatan intersepsi cahaya matahari yang digunakan selama proses fotosintesis. Dengan demikian, diduga perlakuan dosis pupuk silika yang tertinggi memicu pertumbuhan tinggi tanaman jika dibandingkan dengan perlakuan tanpa pupuk silika (kontrol).

\section{Jumlah Anakan}

Jumlah anakan pada tanaman hanjeli merupakan ciri pertumbuhan tanaman dalam mendukung produktivitas dan kesehatan tanaman. Pola anakan yang diamati menunjukkan bahwa pemupukan NPK yang lazim digunakan sebagai dosis anjuran dan dikombinasikan dengan pupuk koloid nano silika menghasilkan anakan yang relatif banyak dan berbeda nyata dengan kontrol atau yang hanya mendapat perlakuan NPK dengan emulsi abu silika (Tabel 2). 
Table 2. Pengaruh pemanfaatan kulit biji hanjeli sebagai pupuk silika organik terhadap tinggi tanaman hanjeli.

\begin{tabular}{lcccc}
\hline \multicolumn{1}{c}{ Perlakuan } & $5 \mathrm{MST}$ & $7 \mathrm{MST}$ & $9 \mathrm{MST}$ & $11 \mathrm{MST}$ \\
\hline Kontrol & $2,83 \mathrm{a}$ & $6,08 \mathrm{a}$ & $8,83 \mathrm{a}$ & $9,25 \mathrm{a}$ \\
NPK Standar & $3,75 \mathrm{a}$ & $6,58 \mathrm{~b}$ & $9,83 \mathrm{~b}$ & $10,08 \mathrm{a}$ \\
NPK + 1/4 emulsi abu silika & $3,42 \mathrm{a}$ & $7,50 \mathrm{c}$ & $11,92 \mathrm{~d}$ & $12,25 \mathrm{bc}$ \\
NPK + 1/2 emulsi abu silika & $3,75 \mathrm{a}$ & $8,17 \mathrm{~d}$ & $12,58 \mathrm{e}$ & $12,92 \mathrm{~cd}$ \\
NPK + 3/4 emulsi abu silika & $3,83 \mathrm{a}$ & $8,83 \mathrm{e}$ & $13,75 \mathrm{~g}$ & $14,67 \mathrm{e}$ \\
NPK + 1 emulsi abu silika & $3,58 \mathrm{a}$ & $9,42 \mathrm{f}$ & $14,92 \mathrm{~h}$ & $15,75 \mathrm{f}$ \\
NPK + 1/4 koloid nano silika & $3,33 \mathrm{a}$ & $7,25 \mathrm{c}$ & $10,75 \mathrm{c}$ & $11,42 \mathrm{~b}$ \\
NPK + 1/2 koloid nano silika & $3,42 \mathrm{a}$ & $8,42 \mathrm{~d}$ & $13,08 \mathrm{f}$ & $13,75 \mathrm{~d}$ \\
NPK + 3/4 koloid nano silika & $2,83 \mathrm{a}$ & $9,75 \mathrm{f}$ & $15,67 \mathrm{i}$ & $16,58 \mathrm{f}$ \\
NPK + 1 koloid nano silika & $3,58 \mathrm{a}$ & $10,58 \mathrm{~g}$ & $17,17 \mathrm{j}$ & $18,00 \mathrm{~g}$ \\
\hline
\end{tabular}

Keterangan: Angka rerata yang diikuti huruf yang sama tidak berbeda nyata berdasarkan Uji Jarak Berganda Duncan pada taraf $5 \%$.

Anakan berasal mata tunas yang tumbuh pada anakan primer, kemudian sekunder dan dari anakan sekunder anakan tersesier. Hal ini dapat dilihat dari perkembangan dan jumlah anakan pada masing-masing fase pertumbuhan. Pada awal pengamatan (5 MST), jumlah anakan masih sama sebanyak 3-5 buah, kemudian pada pengamatan 7 MST jumlah anakan berganda dan menunjukkan perbedaan jumlah. Namun pada pengamatan ke 9 MST dan 11 MST jumlah anakan bervariasi dan menunjukkan adanya perbedaan pengaruh dari masing-masing perlakuan. Pada umur 56 HST (fase vegetatif akhir) jumlah anakan produktif yang lebih banyak diperlihatkan oleh perlakuan NPK + 1 koloid nano silika. Hal ini sejalan dengan hasil penelitian Amrullah (2015), yaitu pemberian silika pada tanaman padi dapat meningkatkan jumlah anakan dan jumlah malai yang dihasilkan.

\section{Serapan P}

Berdasarkan hasil uji statistik ternyata pemberian pupuk NPK dengan pupuk silika organik berpengaruh nyata terhadap kontrol, dan Perlakuan NPK +1 koloid nano silika memberikan hasil serapan $\mathrm{P}$ tertinggi sebesar $0,61 \mathrm{~g} /$ tanaman. Hal ini dapat dilihat pada Tabel 7. Pemberian perlakuan pupuk NPK dan pupuk silika organik menyebabkan perbedaan kandungan $\mathrm{P}$ dalam jaringan tanaman. Kandungan $\mathrm{P}$ pupus tanaman hanjeli meningkat sejalan dengan peningkatan dosis pupuk silika organik. Hal ini sejalan dengan (Yang et al. 2008) bahwa Pemberian Si yang disertai dengan $\mathrm{P}$ dapat meningkatkan kemampuan penyerapan tanaman dan penggunaan $\mathrm{P}$ pada akar tanaman, kandungan dan akumulasi $\mathrm{P}$, bahan kering meningkat, serta memperbaiki kandungan klorofil dan laju fotosintesis pada daun.
Tabel 3. Pengaruh pemanfaatan kulit biji hanjeli sebagai pupuk silika organik terhadap serapan $\mathrm{P}$ tanaman hanjeli vegetatif maksimum.

\begin{tabular}{lc}
\hline \multicolumn{1}{c}{ Perlakuan } & $\begin{array}{c}\text { Serapan P } \\
(\mathrm{g} / \text { tanaman })\end{array}$ \\
\hline Kontrol & $0,22 \mathrm{a}$ \\
NPK Standar & $0,30 \mathrm{~b}$ \\
$\mathrm{NPK}+1 / 4$ emulsi abu silika & $0,36 \mathrm{~cd}$ \\
$\mathrm{NPK}+1 / 2$ emulsi abu silika & $0,40 \mathrm{de}$ \\
$\mathrm{NPK}+3 / 4$ emulsi abu silika & $0,46 \mathrm{fg}$ \\
$\mathrm{NPK}+1$ emulsi abu silika & $0,51 \mathrm{gh}$ \\
$\mathrm{NPK}+1 / 4$ koloid nano silika & $0,33 \mathrm{bc}$ \\
NPK + 1/2 koloid nano silika & $0,43 \mathrm{ef}$ \\
NPK + 3/4 koloid nano silika & $0,54 \mathrm{~h}$ \\
NPK + 1 koloid nano silika & $0,61 \mathrm{i}$
\end{tabular}

Keterangan: Angka rerata yang diikuti huruf yang sama tidak berbeda nyata berdasarkan Uji Jarak Berganda Duncan pada Taraf $5 \%$

\section{Serapan $\mathrm{Si}$}

Pemberian perlakuan pupuk NPK dan pupuk silika organik menyebabkan perbedaan kandungan Si dalam jaringan tanaman. Kandungan Si pupus tanaman hanjeli meningkat sejalan dengan peningkatan dosis pupuk NPK dan pupuk silika organik yang diberikan. Peningkatan serapan Si dengan semakin banyaknya pupuk Si yang diberikan tersebut selain itu juga karena tanaman hanjeli dikenal sebagai tanaman yang banyak menyerap unsur Si (Nurmala, 1998). Hal ini dapat dilihat pada Tabel 4.

Unsur Si diserap tanaman dan didistribusikan ke seluruh bagian tanaman, meskipun akumulasinya berbeda pada setiap bagian tanaman (Richmond \& Sussman, 2003). Pada 
penelitian ini, pemberian Si disemprotkan ke bagian pupus tanaman, sehingga $\mathrm{Si}$ diserap tanaman melalui pori-pori dinding sel tanaman, melalui stomata daun. stomata secara difusi dan selanjutnya masuk ke dalam sel-sel kloroplas baik yang ada di dalam sel-sel penjaga, mesofil maupun seludang pembuluh.

Tabel 4. Pengaruh pemanfaatan kulit biji hanjeli sebagai pupuk silika organik terhadap serapan $\mathrm{Si}$ tanaman hanjeli vegetatif maksimum.

\begin{tabular}{lc}
\hline Perlakuan & Serapan $\mathrm{Si}(\mathrm{g} /$ tanaman) \\
\hline Kontrol & $3,04 \mathrm{a}$ \\
$\mathrm{NPK}$ Standar & $3,79 \mathrm{~b}$ \\
$\mathrm{NPK}+1 / 4$ emulsi abu silika & $4,54 \mathrm{~cd}$ \\
$\mathrm{NPK}+1 / 2$ emulsi abu silika & $5,04 \mathrm{de}$ \\
$\mathrm{NPK}+3 / 4$ emulsi abu silika & $5,78 \mathrm{fg}$ \\
$\mathrm{NPK}+1$ emulsi abu silika & $6,20 \mathrm{~g}$ \\
$\mathrm{NPK}+1 / 4$ koloid nano silika & $4,20 \mathrm{bc}$ \\
$\mathrm{NPK}+1 / 2$ koloid nano silika & $5,44 \mathrm{ef}$ \\
$\mathrm{NPK}+3 / 4$ koloid nano silika & $7,00 \mathrm{~h}$ \\
$\mathrm{NPK}+1$ koloid nano silika & $7,56 \mathrm{~h}$ \\
\hline Keterangan: Angka rerata yang diikuti huruf yang sama tidak \\
\multicolumn{2}{c}{ berbeda nyata berdasarkan Uji Jarak Berganda } \\
\multicolumn{2}{c}{ Duncan pada Taraf 5\%. }
\end{tabular}

Proses masuknya unsur hara melalui daun terjadi karena adanya perpindahan zat dari konsentrasi tinggi ke konsentrasi rendah (difusi) dan perpindahan air melalui membran semi permiabel dari larutan yang mengandung banyak air ke larutan sedikit air (osmosis). Pemupukan lewat daun diaplikasikan melalui bagian bawah permukaan daun dan dilakukan ketika tekanan turgor meningkat pada dinding sel penjaga, sehingga lubang stomata akan membuka secara perlahan (Agustina, 2004).

\section{Hasil Hanjeli}

Tanaman hanjeli yang tumbuh pada kondisi lingkungan tumbuh yang sama namun berbeda perlakuan telah menunjukkan adanya perbedaan terhadap hasil (Tabel 5). Hasil bobot biji per rumpun pada perlakuan kontrol berbeda nyata dibandingkan dengan perlakuan lainnya. Pemberian pupuk NPK + 1 pupuk koloid nano silika menghasilkan bobot biji yang tertinggi. Hal ini diduga keberadaan silika, baik yang berupa emulsi abu silika maupun yang berupa koloid nano silika memberikan pengaruh yang baik pada pertumbuhan tanaman.

Hara Si termasuk dalam kategori hara fungsional yang bisa memperkaya pertumbuhan tanaman dengan mendorong proses fisiologi (Savant et al., 1999). Sejalan dengan penelitian Amrullah (2015) tanaman yang diberi silika terutama yang diberi nano silika, memiliki berat 1000 butir gabah yang lebih tinggi dibanding tanaman kontrol yang tidak diberi silika. Hal ini ada indikasi bahwa lebih beratnya gabah yang dihasilkan tersebut disebabkan oleh adanya akumulasi kandungan silika pada sekam atau kulit yang menyelubungi gabah.

Tabel 5. Pengaruh pemanfaatan kulit biji hanjeli sebagai pupuk silika organik terhadap hasil tanaman padi per rumpun.

\begin{tabular}{lcc}
\hline Perlakuan & Bobot biji (g/rumpun) & Bobot biji (ton/ha) \\
\hline Kontrol & $112,27 \mathrm{a}$ & 2,99 \\
NPK Standar & $118,47 \mathrm{ab}$ & 3,16 \\
NPK + 1/4 emulsi abu silika & $129,84 \mathrm{bc}$ & 3,46 \\
NPK + 1/2 emulsi abu silika & $136,30 \mathrm{~cd}$ & 3,63 \\
NPK + 3/4 emulsi abu silika & $157,96 \mathrm{e}$ & 4,21 \\
NPK + 1 emulsi abu silika & $173,11 \mathrm{f}$ & 4,62 \\
NPK + 1/4 koloid nano silika & $121,99 \mathrm{ab}$ & 3,25 \\
NPK + 1/2 koloid nano silika & $148,16 \mathrm{de}$ & 3,95 \\
NPK + 3/4 koloid nano silika & $181,93 \mathrm{f}$ & 4,85 \\
NPK + 1 koloid nano silika & $210,63 \mathrm{~g}$ & 5,62 \\
\hline
\end{tabular}

Keterangan: Angka rerata yang diikuti huruf yang sama tidak berbeda nyata berdasarkan Uji Jarak Berganda Duncan pada taraf $5 \%$. Bobot biji per hektar tidak diuji statistik sehingga tidak memiliki notasi. 


\section{SIMPULAN}

1. Pemanfaatan kulit biji hanjeli sebagai pupuk silika organik berpengaruh nyata terhadap tinggi tanaman, jumlah anakan per rumpun, serapan $\mathrm{P}$, serapan Si dan hasil hanjeli.

2. Perlakuan NPK +1 nano koloid silika membeikan hasil tertinggi terhadap Serapan P, Si tanaman dan hasil hanjeli sebesar 0,61 g/tanaman, 7,56 g/tanaman, dan 210,63 g/tanaman.

\section{DAFTAR PUSTAKA}

Agustina, L. 2004. Nutrisi Tanaman. Jakarta, Renika Cipta.

Amrullah. 2015. Pengaruh Nano Silika terhadap Pertumbuhan, Respon Morfofisiologi dan Produktivitas Tanaman Padi (Oryza sativa L.). Disertasi. Institut Pertanian Bogor. Bogor [Tidak dipublikasikan]

Badan Pusat Statistik Jakarta Pusat. 2014. Statistik Indonesia Tahun 2010. Jakarta Pusat. Badan Pusat Statistik

Badan Pusat Statistik. 2016. Impor Beras Menurut Negara Asal Utama, 2010-2014. Tersedia online pada https://www.bps.go.id/linkTabelStatis/view/ id/1043. (diakses Desember 2016)

Balai Besar Litbang Sumberdaya Lahan Pertanian. 2006. Sifat Fisik Tanah dan Metode Analisisnya. Balai Besar Penelitian dan Pengembangan Sumber Daya Lahan Pertanian. Badan Penelitian dan
Pengembangan Pertanian. Departemen Pertanian, Bogor.

Lingga, P, dan Marsono. 2007. Petunjuk Penggunaan Pupuk. Edisi Revisi. Penebar Swadaya, Jakarta.

Martanto. 2001. Pengaruh abu sekam terhadap pertumbuhan tanaman dan intensitas penyakit layu fusarium pada tomat. Jurnal Irian Jaya Agro. 8:37-40.

Nurmala, T. 1998. Serealia Sumber Karbohidrat Utama. PT. Rineka Cipta, Jakarta.

Nurmala, T. 2011. Potensi dan prospek pengembangan hanjeli (Coix lacryma-jobi L.) sebagai pangan bergizi kaya lemak untuk mendukung diversifikasi pangan menuju ketahanan pangan mandiri. Jurnal Pangan. 20(1):41-48.

Richmond, and M Sussman. 2003. Got silicon? The non-essential beneficial plant nutrient. Current Opinion in Plant Biology. 6:268272.

Rosmarkam, A, dan NW Yuwono. 2002. Ilmu Kesuburan Tanah. Kanisius, Yogyakarta.

Savant, NK, GH Korndorfer, LE Datnoff, and GH Snyder. 1999. Silicon nutrition and sugarcane production: A review. Journal Plant and Nutrition. 22(12):1853-1903.

Yang, Y, J Li, H Shi, Y Ke, J Yuan, and Z Tang. 2008. Alleviation on low -P stressed maize seedling under hydroponic culture conditions. World Journal of Agri Sci. 4(2):168-172 